\title{
Os levantamentos amostrais mobilizando conhecimentos para a aprendizagem em Estatística Básica
}

Sample surveys mobilizing knowledge for learning in Basic Statistics

Mario de Souza Santana ${ }^{1}$

Fabiano Rosa de Magalhães ${ }^{2}$

Rudney Carlos da Mata ${ }^{3}$

\section{Resumo}

O presente artigo tem como propósito apresentar um produto educacional voltado para o ensino e aprendizagem da Estatística em disciplinas introdutórias nos cursos superiores. Tal produto tem sua origem em experiências didáticas realizadas nos cursos de Administração e de Gestão Ambiental, em um Instituto Federal de Educação Técnica e Tecnológica, no período de 2013 a 2015. No primeiro semestre letivo de 2016 realizamos nova intervenção com a finalidade intencional de um estudo mais sistemático acerca dessas experiências. Concluímos que os surveys se apresentam como uma possibilidade efetiva para o desenvolvimento de uma proposta didática que visa ao desenvolvimento do pensamento estatístico e que tem como fundamento a aprendizagem por meio do uso de investigações reais no ambiente da sala de aula.

Palavras-chave: Pensamento estatístico. Survey. Produto educacional.

\begin{abstract}
This article aims to present an educational product focused on the teaching and learning of Statistics in introductory courses in higher education. They are based on didactic experiences in the courses of Administration and Environmental Management, in an Institute of Technical and Technological Education (Instituto de Educação Técnica e Tecnológica), from 2013 to 2015. In the first semester of 2016, a new intervention is carried out with an intentional purpose of a more detailed study of those experiences. We conclude that the surveys have, as one of the effective possibilities, the development of a didactic proposal that aims the development of statistical thinking as well as learning through the use of investigations.
\end{abstract}

Keywords: Statistical thinking. Survey sampling. Educational product.

\section{Introdução}

Intencionamos nesse artigo apresentar o produto educacional resultante de uma pesquisa que teve sua gênese no desejo de realizar estudo mais sistemático

1 Mestre em Educação Matemática, docente, Instituto Federal do Norte de Minas Gerais, mario.santana@ifnmg.edu.br.

2 Mestre em Matemática, docente, Instituto Federal do Norte de Minas Gerais, rudney.mata@ifnmg.edu.br.

3 Mestre em Ciências Sociais, docente, Instituto Federal do Norte de Minas Gerais, fabiano.magalhaes@ifnmg.edu.br. 
acerca de experiências didático-pedagógicas que vinham sendo implementadas no ensino (e aprendizagem) da Estatística no curso de Bacharelado em Administração e no curso de Tecnologia em Gestão Ambiental do Instituto Federal do Norte de Minas Gerais, Campus Araçuaí, de 2013 a 2015.

Tais experiências já haviam sido também aplicadas em outros contextos e níveis de ensino e apresentadas/discutidas em eventos científicos da área da Educação Matemática (por exemplo, em Santana, 2013; 2016a), tendo sua origem na dissertação de mestrado de um dos autores do presente artigo. Dessas experiências anteriores resultou também um produto educacional, como pode ser visto em Santana (2016b), voltado para a Educação Básica, especialmente para o ensino médio.

Nos apropriamos, então, das ideias que sustentaram a construção da proposta didática do ciclo investigativo defendido na referida dissertação (Santana, 2011) adequando-a, porém, ao ensino superior e aplicando-a na disciplina de Estatística Básica. A mudança de nível de ensino, por si só, não constituiu, contudo, razão para as inquietações que motivaram nossa pesquisa. Porém, algumas particularidades e necessidades emergentes que o contexto muitas vezes impõe é que vinham provocando tais inquietações. Por exemplo: quais conteúdos curriculares emergem nas atividades investigativas - pois quando se dá abertura aos estudantes para escolherem o que pesquisar, seus estudos podem tomar caminhos diversos - e devem ser priorizados e, por conseguinte, o docente precisará dominar/conhecer? Quais dificuldades e limitações são postas pelo contexto escolar onde a proposta é implementada? Entre outros. Acrescenta-se a isso a crença no professor como um agente críticoreflexivo de sua própria prática pedagógica que deve buscar, autônoma e/ou colaborativamente, subsídios teóricos e práticos que o ajudem a compreender e a enfrentar os problemas e desafios do trabalho docente (FIORENTINI; NACARATO, 2005). Dessa forma, julgamos necessário dirigir um olhar mais sistemático para essas práticas, o do pesquisador, com vistas a dar um caráter 
mais científico a todo o processo e maior legitimidade aos resultados de modo a aprimorar e, também, a democratizar seu uso por parte de outros educadores.

Nessa pesquisa foi realizada nova intervenção aplicando-se as atividades em uma turma de $3^{\circ}$ período/semestre do curso de Gestão Ambiental, no campus Araçuaí do Instituto Federal do Norte de Minas Gerais, onde o pesquisador, um dos autores desse artigo, assumiu a figura de professor-pesquisador, uma vez que o mesmo era o docente responsável pela disciplina. Assim, os dados foram coletados no decurso das aulas, ao longo do primeiro semestre letivo de 2016. Os instrumentos utilizados para a coleta dos dados foram: os escritos produzidos pelos estudantes, diário de campo e entrevistas realizadas com os estudantes, que foram gravadas em áudio e, posteriormente, transcritas e analisadas.

Na matriz curricular do curso há apenas uma disciplina de Estatística para a qual não há exigência de pré-requisito. Sua carga horária é de 80 horas-aula e a ementa prevê elementos de estatística descritiva, correlação e regressão linear e elementos da Inferência estatística, incluindo conceitos fundamentais de Probabilidade, Distribuições de Probabilidade, Variáveis aleatórias, Estimação e Testes de Hipóteses. Inclui, ainda, amostragem e a utilização do software Excel para o cálculo das técnicas estudadas.

O arcabouço metodológico que norteia as aulas tem seu início em um tema a ser problematizado e estudado através de um processo de investigação estatística, conforme discorreremos mais adiante. Desse modo, a partir de um problema que deva suscitar a necessidade de coleta de dados, desencadeia-se 0 planejamento da investigação decidindo, por exemplo, se será feita por meio de censo ou amostragem, elaborando-se o instrumento para coleta e o plano amostral, realizando-se entrevistas, entre outros. Coletados os dados, passa-se à organização representando-os e interpretando-os, isto é, fazendo-se as análises exploratórias, com foco no problema estabelecido. Por fim, a tomada de decisões onde serão feitas inferências e tiradas as conclusões. Nesse contexto, a cada fase do ciclo investigativo são operacionalizadas diversas atividades 
concernentes às investigações dos temas propostos pelos estudantes e os conteúdos estatísticos vão se materializando ao longo das mesmas.

Queremos, então, no presente artigo, enfocar no produto educacional resultante de nossa pesquisa apresentando a prática dos surveys como uma possibilidade de atividade investigativa com vistas à aprendizagem de conteúdos centrais de Estatística Básica e tendo em mente a promoção de uma aprendizagem contextualizada e mais significativa.

\section{Pensamento estatístico nas investigações empíricas}

Temos utilizado uma metodologia de ensino (e aprendizagem) baseada na ideia do ciclo investigativo. Tal proposta fundamenta-se no pensamento estatístico envolvido nas investigações empíricas, na perspectiva de estrutura proposta por Wild e Pfannkuch (1999), e está em consonância com aquelas citadas na seção anterior.

A noção de ciclo investigativo emerge, portanto, da estrutura de pensamento estatístico envolvido nas investigações empíricas proposta por Wild e Pfannkuch (1999). De acordo com os autores, tal estrutura foi construída com base na literatura, na experiência própria e em entrevistas realizadas com estudantes de estatística envolvidos em projetos de pesquisa e com estatísticos profissionais em exercício. Essa estrutura é composta por quatro dimensões, a saber: o ciclo investigativo, tipos de pensamento, o ciclo interrogativo e as disposições.

Wild e Pfannkuch (1999) afirmam que a primeira dimensão é uma adaptação do modelo PPDAC (Problem, Plan, Data, Analysis, Conclusions) de Mackay e Oldford (1994) e se relaciona com a forma como uma pessoa atua e o que pensa durante o curso de uma investigação estatística. Essa dimensão evidencia a importância da formulação do problema, inserido em um dado contexto, e do planejamento do sistema de medição, plano amostral etc., etapas iniciais do modelo. Além disso, o conhecimento obtido e as necessidades 
identificadas dentro do ciclo podem originar novos ciclos investigativos (Quadro 1).

\begin{tabular}{|c|c|c|c|c|}
\hline Problema & Planejamento & Dados & Análise & Conclusão \\
\hline - Completa & - Sistema de & - Coleta de & - Análise & - Interpretação- \\
compreensão da & medição & dados & exploratória & Conclusão \\
dinâmica do & - Desenho & - Gerenciamento & - Análises & - Novas \\
sistema & amostral & dos dados & planejadas & ideias \\
- definição do & - Gerenciamento & - Purificação dos & - Análises & - Comunicação \\
problema & dos dados & dados & emergentes & \\
& - Orientação e & & - Hipóteses & \\
& análise & & & \\
\hline
\end{tabular}

Quadro 1 - Esquema do ciclo investigativo

Fonte: Wild; Pfannkuch, 1999.

Para Silva (2007), este modelo, no tocante à sala de aula, objetiva que o estudante sinta necessidade de resolver um problema, o que poderá garantir seu envolvimento. Dessa forma, o problema deixaria de ser resolvido apenas porque 0 professor o pede, pois o estudante estando envolvido passaria a desejar a solução e buscaria ferramentas necessárias para isso.

As outras dimensões dessa estrutura têm se configurado, principalmente, como orientações na condução e planejamento em várias etapas do processo e nas reflexões críticas sobre aquilo que se está fazendo.

Com isso em mente, destacamos que há os tipos de pensamento, $2^{\mathrm{a}}$ dimensão da estrutura proposta, categorizados e agrupados por Wild e Pfannkuch (1999) em fundamentais e gerais.

Os tipos fundamentais de pensamento estatístico, de acordo com a estrutura proposta pelos autores, se referem:

1) a reconhecer a necessidade dos dados, uma vez que nossas experiências pessoais podem ser insuficientes para fundamentar tomadas de decisão. Fazer isso com base em dados deliberadamente coletados são um impulso estatístico/científico;

2) à Transnumeração, que perpassa todas as análises de dados estatísticos ocorrendo cada vez que mudamos nossa maneira de observar os dados para que isso nos conduza a novos significados sendo, portanto, um processo dinâmico de mudança de representações para engendrar compreensão; 
3) à Variação, que é de grande importância para a definição do pensamento estatístico. Ela é onipresente e pode ter sérias consequências práticas e a Estatística nos dá um meio de entender um mundo caracterizado pela mesma. Ela é a razão pela qual as pessoas tiveram que desenvolver métodos estatísticos sofisticados para filtrar mensagens de dados do ruído externo. Os estatísticos modelam a variação com os propósitos de predição, explicação ou controle;

4) a um conjunto distinto de modelos (estatísticos): todos os pensamentos usam modelos e a principal contribuição da Estatística para o pensamento tem sido o seu próprio conjunto característico de modelos, de estruturas para reflexão sobre certos aspectos da investigação de uma forma genérica. Em particular, os métodos para design e análise do estudo têm sido desenvolvidos a partir de modelos matemáticos que incluem componentes aleatórios;

5) à Matéria-prima com que trabalha o pensamento estatístico, que são o conhecimento estatístico, conhecimento do contexto e a informação oriunda dos dados. O pensamento em si é a síntese desses elementos para produzir implicações, ideias e conjecturas. Desse modo, os tantos exemplos utilizados no ensino da Estatística construídos em um panorama árido, livre de contexto, garantem que um grande número de estudantes nunca engaje no pensamento estatístico. Os autores trazem essa reflexão e explicam que as etapas iniciais são conduzidas quase completamente pelo conhecimento do contexto e que o conhecimento estatístico contribui mais à medida que o pensamento se materializa e se estabelece um diálogo constante nas esferas do contexto e da Estatística por meio do processo PPDAC.

Os tipos gerais de pensamento são:

1) o Estratégico: que está relacionado com o planejamento: o que fazer? Como fazer? Tem a ver com antecipação de problemas a fim de evitá-los; leva em conta as limitações sob as quais se está trabalhando. Discutiremos mais adiante sobre essas limitações, uma vez que podem configurar-se como restrições à profundidade e qualidade do pensamento estatístico; 
2) a Modelagem: construir modelos e usá-los para compreender e prever o comportamento de aspectos do mundo que nos preocupam parece ser uma maneira geral do pensamento. Informações buscadas e obtidas da realidade do contexto às vezes estão nos dados estatísticos. Constroem-se, então, modelos estatísticos para ter uma visão dessa informação, que retroalimenta o modelo mental;

3) a Aplicação de técnicas: a estratégia de se abordar um problema com base em problemas arquétipos aplicando ou adaptando sua solução é comumente utilizada em estatística. A implementação dessa estratégia ou a aplicação prática de qualquer técnica envolve reconhecimento, aplicação do método e interpretação no contexto, de maneira cíclica.

A terceira dimensão da estrutura proposta por Wild e Pfannkuch (1999) concerne a um ciclo interrogativo que diz respeito aos questionamentos e às críticas a ideias e informações enquanto se resolve problemas. O pensador deve imaginar e ter ideais para gerar possibilidades, que pode ser a partir do contexto, dos dados ou do conhecimento estatístico; buscar internamente (conhecimento próprio) ou externamente (na literatura, consultando outras pessoas etc.) essas ideias e informações; extrair e processar os resultados da busca visando a encontrar relações entre as ideias e a ampliação dos modelos mentais para compreender essas inter-relações; julgar a confiabilidade das informações, a utilidade das ideias, a necessidade de mais investigações etc. para tomar decisão sobre o que deve ser mantido e o que deve ser descartado. É, portanto, um processo genérico de pensamento, de uso constante, na resolução de problemas estatísticos.

A quarta dimensão refere-se às disposições. Está relacionada a qualidades pessoais que afetam a entrada nos modos de pensamento. Deve-se ter: (a) Curiosidade e consciência: Perceber e questionar: por quê? Como isso aconteceu? Isto é algo que acontece em geral? Como posso aproveitar isso?; (b) Compromisso: este intensifica os outros elementos de disposição. Refere-se a alguma conexão pessoal com o problema. Se o problema é interessante, ou 
importante, a curiosidade, a consciência, a imaginação ou a perseverança ficam mais aguçados; (c) Imaginação: a formação de modelos mentais que capturam a dinâmica essencial do problema é profundamente imaginativa; (d) Ceticismo: conduz a que se critiquem as ideias, informações ou planejamentos. Questiona-se a adequação das medições, do design do estudo, a qualidade dos dados, método de análise, ou se as conclusões alcançadas estão justificadas nos dados; (e) Ser lógico: a capacidade para detectar quando uma ideia segue a partir de outra e quando não, e para construir um argumento lógico é claramente importante para todo o pensamento. O raciocínio lógico é o caminho para se chegar a conclusões válidas.

Wild e Pfannkuch (1999) destacam, ainda, a existência de restrições que limitam a profundidade e a qualidade do pensamento. De acordo com eles, algumas dessas restrições advêm de fatores internos ao pensador e outras do entorno. Baixos níveis de habilidade nos tipos de pensamento envolvidos e nas atitudes mencionadas na dimensão de Disposições, pobres habilidades de comunicação, falta de perseverança ou confiança, são exemplos que concernem ao primeiro tipo de restrição. Além disso, reforçam que muito do que julgamos conhecer, nossas preconcepções, pode nos cegar diante de outras possibilidades, insensibilizar-nos em face de informações relevantes dificultando o discernimento. Outras restrições estão relacionadas à falta de tempo, dinheiro e materiais.

Aspectos importantes da natureza do conhecimento estatístico se manifestam na estrutura descrita. Defendemos que podem ser considerados no ensino e aprendizagem de Estatística. A partir de um problema que deva suscitar a coleta de dados - necessidade dos dados - desencadeia-se o planejamento para a investigação decidindo, por exemplo, se será feita por meio de censo ou amostragem, elaborando o instrumento para coleta, realizando entrevistas, entre outros. Coletados os dados, passa-se à organização representando-os e interpretando-os, isto é, fazendo as análises, com foco no problema estabelecido. 
Por fim, a tomada de decisões onde serão feitas inferências e tiradas as conclusões.

As demais estruturas do pensamento perpassam toda a condução do processo sobressaindo algumas em certo momento da investigação, mas sempre como fio condutor das várias etapas percorridas ao longo do processo de investigação.

Adicionalmente, nessa última experiência, incluímos um caráter interdisciplinar na proposta didática implementada. Isso se deu através da participação de outros docentes, membros da equipe do projeto de pesquisa, especialmente na fase de problematização/contextualização do ciclo investigativo, propondo temas da área de formação dos estudantes para serem investigados através da abordagem quantitativa das pesquisas, com vistas ao desenvolvimento do pensamento estatístico.

Nessa conjuntura, a problematização dos temas pode remeter a distintas abordagens de pesquisa - por exemplo: levantamentos e experimentos. Trataremos em seguida dos surveys (sampling), apresentando algumas características dos mesmos e, ao final, indicando sua importância e convergência com nossa proposta. Desse modo, os evidenciaremos como opção de prática no ambiente da sala de aula com vistas ao alcance de nossos propósitos no ensino e aprendizagem na disciplina de Estatística Básica.

\section{Surveys}

Tal como explica Babbie (1999), também usaremos aqui o termo survey com o sentido implícito de "survey sampling", de levantamento por amostragem. Tipicamente, como afirma o mesmo autor, métodos de survey são usados para estudar um segmento ou parcela - uma amostra - de uma dada população com o propósito de fazer estimativas sobre a natureza da mesma, isto é, da população total da qual a amostra foi selecionada. Assim, por exemplo, consultam-se cerca de 2000 eleitores para predizer como dezenas de milhões votarão no dia da 
eleição presidencial; consulta-se uma amostra de consumidores visando a conhecer preferências e comportamentos de consumidores em geral.

Em linhas gerais, num survey típico seleciona-se uma amostra; um questionário é elaborado; os questionários são aplicados à amostra através de entrevistas (pessoais, por telefone ou correio); as respostas são codificadas de forma padronizada e registradas de forma quantitativa; transferem-se as respostas para um software; os registros padronizados são submetidos a uma análise agregada fornecendo descrições e determinando correlações entre diferentes respostas; as conclusões descritivas e explicativas obtidas pela análise são, então, generalizadas para a população da qual a amostra foi selecionada (BABBIE, 1999).

Babbie (1999) destaca que o survey se refere a um tipo particular de pesquisa social empírica, mas que há muitos tipos. Porém, três objetivos gerais os permeiam: descrição, explicação e exploração. De acordo com o autor, surveys são frequentemente realizados para permitir enunciados descritivos sobre alguma população de modo a descobrir a distribuição de certas características e atributos. Nesse sentido, o pesquisador não visa ao porquê de a distribuição observada existir, mas ao que ela é. Ainda de acordo com o autor, a despeito da maioria dos surveys visar, pelo menos em parte, à descrição, muitos têm o propósito adicional de fazer asserções explicativas sobre a população. Explicar quase sempre requer a análise multivariada. Surveys podem ainda fornecer um mecanismo de busca quando se está começando a investigação de algum tema, isto é, permite um estudo exploratório inicial.

Há dois desenhos básicos de surveys e mais algumas variações destes. De acordo com Babbie (1999), no survey denominado interseccional - desenho de pesquisa mais frequentemente usado -, os dados amostrais são coletados num certo momento visando a descrever alguma população maior apenas naquela mesma ocasião. É o caso das pesquisas de intenção de voto ou da pesquisa de emprego e desemprego a qual descreve a situação da população na época do estudo. Tal survey pode ser usado não somente para descrever, mas 
também para determinar relações entre as variáveis na época do estudo (BABBIE, 1999).

Por outro lado, alguns desenhos de surveys, descritivos ou explicativos, permitem análise de dados ao longo do tempo sendo que os mesmos são coletados em tempos diferentes com a finalidade de identificar mudanças nas descrições e explicações. Esse tipo de desenho é denominado survey longitudinal, são os estudos de tendência, de coortes e de painel.

No tocante à sala de aula, o ideário pedagógico que nos apropriamos tem implicado no uso de investigações reais no ensino e aprendizagem da Estatística. Temos implementado uma metodologia baseada no ciclo investigativo a qual tem nos levado a uma abordagem contextualizada com os conceitos emergindo do caráter investigativo das atividades, surgindo à medida que se estuda determinado tema escolhido, geralmente, pelos próprios estudantes e aplicandose as técnicas estatísticas.

Das possíveis abordagens de pesquisa (quantitativa) que temos observado surgir dos temas propostos dos estudantes, desde 2013, a grande maioria tem conduzido aos levantamentos amostrais. Delineamentos experimentais raramente surgiram. A Análise de Séries Temporais apareceu em algumas propostas apenas sendo levada adiante uma vez somente (que julgamos de grande relevância no contexto do curso de gestão ambiental, mas que não é foco no presente artigo). Destarte, considerando as técnicas estatísticas necessárias para se investigar certo problema, levando-se em conta se determinada investigação é exequível no decurso de um semestre, além de considerar, é claro, a ementa da disciplina e os fundamentos teórico-metodológicos que nos guia, percebemos que o uso dos surveys tem nos propiciado uma boa adequação a esses propósitos.

Nesse sentido, destacamos que Bolfarine e Bussab (2005) apresentam e discutem uma lista de tópicos a serem considerados numa investigação estatística, bastante útil no contexto do ciclo investigativo, arcabouço metodológico de nossa proposta didática. Os autores exibem uma série de medidas e cuidados que se deva tomar antes da realização, durante a aplicação e 
depois da pesquisa efetuada. Alertam ainda que um 'checklist' não consegue prever todas as possíveis situações de um mundo tão rico e complexo como as pesquisas quantitativas, podendo ser usado como um guia, mas que não implica necessariamente uma sequência ordenada de passos a serem seguidos. Podemos destacar: a questão a ser investigada; estabelecimento da populaçãoalvo; as variáveis e atributos; parâmetros populacionais; tipo de investigação - por exemplo, censo ou amostragem; modo de coleta - entrevista direta, telefone, internet etc.; elaboração de questionário; planejamento e seleção da amostra; treinamento dos entrevistadores; preparação dos dados; análises estatísticas; apresentação dos resultados; divulgação do banco de dados. Na próxima seção abordaremos em detalhes a operacionalização das fases do ciclo - da problematização às conclusões - e as atividades implementadas, que constituem o produto educacional resultante desses anos de atividades e da análise mais sistemática da pesquisa realizada.

\section{0 produto}

As fases do ciclo investigativo (mostradas na figura 1 anteriormente apresentada) têm sido operacionalizadas tomando como arcabouço o conjunto de atividades sugeridas por Santana (2012) (mas não necessariamente nos limitando a elas), quais sejam: 1 Problematização: divisão da turma em grupos; escolha dos temas; estudos sobre o tema (levantamento bibliográfico) e estabelecimento dos objetivos (ou questões problema) do estudo. 2 Planejamento: população alvo; censo x amostragem; plano de amostragem; variáveis; instrumento de coleta (questionário); discussão sobre os erros não amostrais e suas influências na pesquisa (procedimentos de campo). 3 Dados: Coleta dos dados; inserção dos dados em planilha eletrônica. 4 Análises univariadas: construção de tabelas e gráficos e sua interpretação; medidas descritivas e interpretação; análises bivariadas. 5 Conclusões: índice e intervalos de confiança e teste de hipóteses; relatórios e divulgação; avaliação da credibilidade dos dados. 


\subsection{A problematização}

Como temos destacado, o uso do ciclo investigativo envolve, necessariamente, a resolução de problemas contextualizados. O ciclo se inicia a partir de um problema e o pensamento estatístico é a síntese do conhecimento estatístico, do conhecimento do contexto e da informação oriunda dos dados (contextualizados). Na Estatística, os dados são vistos como números em um contexto, decorrendo daí a necessidade do trabalho com dados reais contextualizando-os por meio de investigações. Como explicam os autores da concepção de pensamento estatístico adotada, as etapas iniciais são conduzidas quase completamente pelo conhecimento do contexto e o conhecimento estatístico contribui mais à medida que o pensamento se materializa e que se estabelece um diálogo constante nas esferas do contexto e da Estatística por meio do processo PPDAC.

Para iniciar o ciclo investigativo dividimos a turma em grupos, em geral com 3 ou 4 estudantes, e procuramos dar voz ativa a eles permitindo que sugiram e escolham os temas a serem investigados. Todavia, para estimulá-los, começamos mostrando algumas possibilidades e dando exemplos de questões que poderiam ser pesquisadas dentro dos temas exemplificados. $O$ intuito é incentivar que deles surjam outras ideias. Nesse momento, os outros docentes podem participar diretamente apresentando exemplos de suas áreas de conhecimento.

Em geral, optamos por ter cada grupo com um tema específico. Mas o professor pode escolher ainda ter um tema único para a turma sendo desdobrado em enfoques de interesse de cada grupo, isto é, cada grupo investiga um objeto distinto ou tema único e objetivo único para todos os grupos (SANTANA, 2012). Todavia, em qualquer uma das situações, cada grupo deve trabalhar separado, cada qual elaborando todas as atividades ao longo da investigação sendo que, findada cada uma, os grupos expõem suas soluções em assembleia. Isso permite que aprendam uns com os outros por meio da comparação e possibilita a percepção de que não necessariamente uma solução apresentada estará somente certa ou errada. Após o debate escolhe-se qual solução entre as 
apresentadas será mais adequada à continuidade da investigação (no caso de todos trabalharem mesmo tema e objetivos).

Definidos os temas, os estudantes devem-se concentrar-se na elaboração de objetivos para o trabalho - na maioria das vezes o geral e os específicos. Tem sido comum nesse início do trabalho os estudantes sentirem certa dificuldade ou ficar meio apreensivos. Primeiramente, por se tratar de uma disciplina, segundo esperam, "matemática", a atividade acaba transparecendo para eles meio estranha. Em segundo lugar, conforme salientam Bolfarine e Bussad (2005), uma das maiores dificuldades de qualquer pesquisa é a formulação correta dos seus objetivos gerais e operacionais, o que exige muito conhecimento específico da área de interesse, muito trabalho de pesquisa bibliográfica e grande habilidade criativa por parte dos pesquisadores envolvidos. Portanto, é natural que alguma dificuldade apareça.

O levantamento teórico-bibliográfico acerca do tema é sempre uma atividade que solicitamos e pedimos que seja feita em seguida a redação de um relatório contendo ele e as atividades até ali realizadas. Sempre sugerimos incluir nesse levantamento teórico estudos semelhantes já feitos. Conforme Bolfarine e Bussab (2005) eles podem configurar-se boas fontes para identificar e operacionalizar objetivos, bem como obter sugestões de como o problema pode ser resolvido. Além disso, no levantamento teórico boas definições dos constructos necessários ao estudo ajudarão bastante na operacionalização dos objetivos no momento da elaboração do sistema de medição.

Por fim, temos observado uma grande variedade de temas escolhidos pelos estudantes. Geralmente, dizem respeito à área de formação dos estudantes (como a Educação Ambiental nas escolas ou a questão do lixo, no curso de Gestão Ambiental, ou pesquisas de mercado, pesquisas de satisfação, no curso de Administração) bem como temas que estão socialmente em evidência naquele momento (como a questão da criminalidade no munícipio, que vinha aumentando assustadoramente; ou o levantamento da opinião da população da cidade e da 
região a respeito de demandas de novos cursos a serem ofertados pela instituição no momento em que se elaborava o Plano de Desenvolvimento Institucional).

Reconhecer a necessidade dos dados fica evidente nessa fase uma vez que os estudantes percebem que não é possível responder aos objetivos colocados apenas por meio de experiências pessoais.

\subsection{O planejamento}

Em geral, colocamos como primeiras atividades do planejamento a escolha do público-alvo - que possibilita apresentar o conceito de população e suas unidades elementares (uma pessoa, família ou o domicílio, estudantes, turmas de estudantes ou escolas, por exemplo) e as diversas populações possíveis (população alvo, população acessível) - e a decisão entre censo ou amostragem - define-se cada qual e discutem-se as vantagens e desvantagens de cada um.

Passamos então à elaboração do sistema de medição. Um dos desafios das pesquisas quantitativas é a criação de bons indicadores (variáveis, escalas) que representem adequadamente os conceitos (constructos) de interesse (BOLFARINE; BUSSAB, 2005). A pesquisa bibliográfica e a habilidade criativa por parte do pesquisador será de grande valia. Também o será pesquisar levantamentos semelhantes realizados anteriormente (caracterizando um tipo geral de pensamento, $A$ aplicação de técnicas - estratégia de se abordar um problema com base em problemas arquétipos). Como afirma Babbie (1999), se a conceituação e a medição de variáveis não são adequadas, correlações observadas entre elas podem não fazer sentido.

Nesse momento o professor apresenta a definição de variáveis, sua classificação - qualitativas ordinal ou nominal e quantitativa discreta ou contínua ,exemplifica mostrando que (e como) as mesmas devem estar diretamente vinculadas a cada objetivo específico colocado.

Assim, pode-se passar à criação do instrumento de coleta, geralmente o questionário. Esse é um momento rico, permeado de criatividade. Os estudantes elaboram perguntas representando as variáveis e criando escalas de medição. 
A primeira parte do questionário exige a identificação de quemb faz a pesquisa: nome da empresa, entrevistador, crítico, supervisor, para compor o controle de dados (data da entrevista, local, tentativas, se houve recusa, se a entrevista foi totalmente ou parcialmente realizada etc.), bem como o seu número (em geral questionários são numerados). Solicitamos então a criação de uma Folha de Rosto contendo alguns desses dados, aqueles de fato necessários ao trabalho. Depois orientamos na criação de uma parte inicial constando a apresentação do questionário, solicitando a colaboração, explicando os objetivos, a promessa de sigilo das informações, algumas orientações para o preenchimento e agradecendo a colaboração. Por fim, discutimos questões específicas para a elaboração das perguntas e os impactos das mesmas na qualidade e confiabilidade dos dados.

Assim, os estudantes elaboram uma primeira versão do questionário. Essa primeira versão pode ser corrigida pelos pares, onde um grupo corrige o de outro apresentando sugestões de melhoria, e pelo professor. Elabora-se, então, uma segunda versão abarcando as correções. Depois, os estudantes realizam um préteste do mesmo aplicando a um certo número de pessoas pertencentes à população alvo e, se necessário, efetuam-se novas correções.

Aqui é sempre interessante observar o pensamento estratégico no sentido da antecipação de problemas a fim de evitá-los. É comum os estudantes elaborarem questões que permitem ao respondente assinalar mais de uma resposta, o que ferirá um princípio básico das variáveis e poderá tornar inviável a análise posterior da mesma. É comum também colocarem questões abertas. Isso implica que, para as análises, terão que observar o conteúdo de cada resposta a fim de codificá-las em categorias.

A atividade seguinte é de elaboração do plano amostral. Será necessário definir as unidades amostrais; o método de seleção dessas unidades (o tipo de amostragem) e o tamanho da amostra. O professor explica questões relativas às amostragens probabilísticas e não-probabilísticas, as principais técnicas, o dimensionamento da amostra e outras questões que julgar necessárias. 
Aqui se pode propor aos grupos a seguinte questão:

Definida a amostragem como o melhor caminho, de que modo então selecionar aleatoriamente a amostra para o estudo? Caso o grupo perceba que as técnicas de amostragem probabilísticas não são convenientes [ou viáveis ou possíveis por não existir um cadastro para sorteio prévio não viciado, por exemplo], justificar o porquê e propor uma alternativa, isto é, uma amostragem não probabilística (SANTANA, 2012, p. 55).

Em nossas experiências o ambiente educacional tem se destacado para as amostragens. É o caso de investigações realizadas no próprio campus ou em escolas do município e/ou região. Nesses casos, por existir listagens dos elementos que compõem a população, tornam-se viáveis as amostragens probabilísticas. Além disso, a aplicação dos questionários fica mais prática uma vez que se pode aplicá-los aos grupos (turmas) de informantes simultaneamente.

Por outro lado, tem sido comum também que os estudantes proponham pesquisas domiciliares (algumas vezes selecionando-os via amostragem por conglomerados) ou nas ruas em pontos de fluxo.

Para finalizar o planejamento da pesquisa, julgamos importante discutir os erros não amostrais - erros de cadastro, erros associados a não resposta e erros de medição e os procedimentos de campo (por exemplo, a postura nas entrevistas). Algumas vezes os estudantes elaboraram uma espécie de manual para o entrevistador.

\subsection{A coleta dos dados}

Passa-se agora à coleta dos dados. Os estudantes realizam as entrevistas ou aplicam os questionários. Se o professor julgar necessário, pode trabalhar atividades paralelas dando mais tempo aos estudantes para a coleta. Deve-se, também, ir preparando as planilhas. Sugerimos o uso do Excel ou do Calc por serem mais acessíveis. Lançar as variáveis nas colunas e utilizar as listas suspensas (validação de dados). Alertar os estudantes quanto à necessidade de padronização. Tão logo se conclua a inserção dos dados dos questionários 
passe-se a elaboração das primeiras construções - tabelas, gráficos, tabelas de dupla entrada, média, mediana, entre outras.

\subsection{As análises}

A partir dos dados inseridos na planilha passamos às análises exploratórias. Essa é uma etapa também muito propícia à exploração de diversas técnicas e conceitos estatísticos a partir do contexto subjacente. É um momento que exige muita criatividade e perspicácia dos estudantes e do professor. Como afirmam Wild e Pfannkuch (1999), a matéria-prima com que trabalha o pensamento estatístico são o conhecimento estatístico, do contexto e a informação oriunda dos dados e que o pensamento em si é a síntese destes elementos para produzir implicações, ideias e conjecturas.

Nessa fase do ciclo investigativo enfocamos a natureza das variáveis a fim de nortear as representações e análises mais adequadas a cada tipo (qualitativa nominal e ordinal e quantitativa discreta e contínua). É possível explorar as tabelas de distribuição de frequência, os gráficos estatísticos, as medidas de tendência central e dispersão e outras medidas descritivas que se fizerem pertinentes. Ao analisar possíveis relações de associação entre as variáveis podemos adentrar nos conceitos de correlação e regressão a partir de dados reais. Nesse cenário, hipóteses acerca das questões investigadas serão levantadas.

Didaticamente, sugerimos primeiro que se realizem análises univariadas descrevendo as variáveis independentemente da ocorrência de outras, análises pertinentes às variáveis qualitativas e às quantitativas. Depois, as análises bivariadas buscando associações entre variáveis (qualitativas com qualitativas, qualitativas com quantitativas e quantitativas com quantitativas).

\subsection{Conclusões}

Nessa fase o trabalho se concentra em elementos de inferência estatística, probabilidades e variáveis aleatórias. É discutida a estimação (pontual e 
intervalar) dos parâmetros populacionais proporcionando aos estudantes compreenderem os índices de confiança e margens de erro nas pesquisas. Também hipóteses levantadas na fase anterior podem ser testadas permitindo operacionalizar as regras e conceitos dos testes clássicos de hipóteses.

Em seguida os estudantes retomam os objetivos colocados no início do estudo a fim de respondê-los chegando às conclusões; constroem relatórios estatísticos descrevendo todas as etapas da pesquisa, apresentando dados e resultados alcançados; apresentam em seminários as investigações. Já a divulgação dos resultados tem variado, algumas vezes limitando-se à sala de aula quando da apresentação dos seminários. Contudo, alguns vão além, apresentando em eventos científicos do campus ou proferindo palestras em escolas de educação básica.

Por fim é feita uma atividade de avaliação/reflexão da confiabilidade dos resultados do estudo. Destacamos ainda que o ciclo interrogativo se faz notável em vários momentos da investigação. E que se o problema investigado for interessante ou importante os elementos de disposição se aguçam.

\section{Considerações}

Propomo-nos nesse artigo apresentar o produto educacional que tem na prática dos surveys em ambiente de sala de aula uma possibilidade de atividade investigativa com vistas à aprendizagem de conteúdos centrais de Estatística Básica tendo em mente a promoção de uma aprendizagem contextualizada e mais significativa.

Acreditamos que tal produto possa ser utilizado em cursos superiores de qualquer área que possua disciplina introdutória de Estatística, pois a contextualização que promove o torna viável em contextos diversos. No caso da formação estatística do professor de matemática podemos crer na sua adequabilidade uma vez que se pode provocar discussões relativas à metodologia de ensino e aprendizagem. 
Temos observado, no entanto, que tal experiência tem suscitado dificuldades e limitações. Já no início nos deparamos com situação de incerteza quanto aos rumos que tudo tomará, incluindo-se os possíveis conteúdos estatísticos que teremos de dar conta para que o trabalho aconteça. Na fase de análise, por exemplo, percebemos que se poderiam aplicar técnicas mais robustas, mas que o tempo não nos permite. As amostragens tem sido outra dificuldade. Estas, entretanto, contribuem muito para o desenvolvimento do pensamento crítico uma vez que os estudantes vivenciam as limitações que impedem o uso de técnicas probabilísticas.

Por fim, é válido salientar que sair da zona de conforto de nossa tradição do ensino da matemática nos leva a aventurarmos em um caminho aberto a possibilidades diversas. Destacamos, porém, que, embora dificuldades permeiem o desenvolvimento desse tipo de atividade - como é o caso dos conteúdos necessários à condução do processo -, a visão de educação (estatística) de que estamos imbuídos será decisiva para se levar a cabo qualquer alternativa metodológica a essa tradição.

\section{Referências}

BABBIE, Earl. Métodos de pesquisas de survey. Trad. Guilherme Cezarino. Belo Horizonte: editora da UFMG, 1999.

BOLFARINE, Heleno; BUSSAB, Wilton Oliveira. Elementos de amostragem. São Paulo: Editora Blucher, 2005.

FIORENTINI, Dario; NACARATO, Adair Mendes. Cultura, formação e desenvolvimento profissional de professores que ensinam matemática: investigando e teorizando a partir de prática. São Paulo: Musa Editora, 2005.

MACKAY, R. J.; OLDFORD, W. Stat 231 Course Notes Fall. Canada: University of Waterloo, 1994. In: WILD, Chris.; PFANNKUCH, Maxine. Statistical thinking in empirical enquiry.

International Statistical Review, Voorburg, n. 67, p. 223-265, 1999. Disponível em: https://iaseweb.org/documents/intstatreview/99.Wild.Pfannkuch.pdf. Acesso em: 07 de novembro de 2008.

SANTANA, Mario de Souza. A Educação Estatística com base num ciclo investigativo: um estudo do desenvolvimento do letramento estatístico de estudantes de uma turma do $3^{\circ}$ ano do Ensino Médio. 2011. 196 f. Dissertação (Mestrado em Educação Matemática). Departamento de matemática, UFOP, Ouro Preto, 2011. 
SANTANA, Mario de Souza. Estatística para professores da educação básica: conceitos e aprendizagem para a cidadania. Curitiba: editora CRV, 2012. 94 p.

SANTANA, Mario de Souza.. Investigações Estatísticas: elementos Didáticos para uma leitura crítica do uso social da linguagem estatística. In: XI Encontro Nacional de Educação Matemática XI ENEM, 2013, Curitiba. Anais do XI Encontro Nacional de Educação Matemática: Educação Matemática - retrospectivas e perspectivas, 2013.

SANTANA, Mario de Souza. O ciclo investigativo como recurso à aprendizagem estatística: um enfoque no pensamento estatístico. In: $12^{\circ}$ Encontro Nacional de Educação Matemática, 2016, São Paulo. Anais do $12^{\circ}$ Encontro Nacional de Educação Matemática, 2016a.

SANTANA, Mario de Souza. Traduzindo Pensamento e Letramento Estatístico em atividades para sala de aula: construção de um produto educacional. Bolema, Rio Claro (SP), v. 30, n. 56, pp. 1165-1187, 2016b.

SILVA, Cláudia Borim. Pensamento estatístico e raciocínio sobre variação: um estudo com professores de matemática. (2007). 354 f. Tese (Doutorado em Educação Matemática). São Paulo: Pontifícia Universidade Católica de São Paulo, 2007.

WILD, Chris; PFANNKUCH, Maxine. Statistical thinking in empirical enquiry. International Statistical Review, n.67, p. 223-65, 1999. 